\title{
Canvas to Improve the Design Process of Educational Animation
}

\author{
André L. Battaiola, Márcia Maria Alves, and Rafael Eduardo Paulin \\ Paraná Federal University - PPGDesign, Design Department - General Carneiro, 460, \\ 80060-150 - Curitiba, Paraná, Brazil \\ \{ufpr.design.profe.albattaiola, alvesmarcia, \\ rafapaulin\} @gmail.com
}

\begin{abstract}
Educational animation as a resource for learning has proliferated due to the inclusion of technology in schools and the possibilities brought by new media and graphic design software. By using animation for learning this feature gains more stakeholders with different goals (learning and teaching) and becomes a complex product. Aiming this, it is necessary to use auxiliary tools to cover all the functions of the project. The Business Model Generation (BMG) is a tool that displays all stakeholders of a business and their relationships. This article tries to apply the idea of this tool as an auxiliary canvas for creating requirements for animation. For those presents the BMG canvas and proposes a canvas for design educational animations. Finally, to show its uses two animation samples were evaluated by the model built, to demonstrate the ability of the canvas to be used as a tool for collaborative requirements elicitation.
\end{abstract}

Keywords: animation, design, educational animation, and canvas.

\section{Introduction}

Nowadays, the use of animations as learning objects has been expanded [1]. The entertainment characteristic of animation helps to improve motivation in the teaching / learning process. On the other hand, the educational animation design becomes more complex, considering that more elements and stakeholders must be taken into account to produce an efficient educational animation.

The stakeholders group includes, basically, four types: content creators (educators in general), designers (animation conception and production), teachers as users (indirect users) and apprentices (direct users).

The design process must consider all requirements of this group, thus this process needs a tool that helps to manage and conciliate decisions in a collaborative way. To solve this problem, this paper proposes the use of a canvas based on the model presented in "Business Model Generation Canvas" [25, 26]. The proposed canvas allows both a modular and a holistic view of all design process. Besides, it allows collaborative design.

In the area of education, the use of Canvas Business Model Generation is also justified because in addition to facilitating the design of materials, it can aid in the analy- 
sis of the context of learners and provide them a better fit of the proposed tasks. The analysis cultural, social and cognitive of users can help the design team elaborate the requirements of the project and put into practice the concepts of learning that focuses on apprentice learner theory (constructivism, constructionism, meaningful learning, situated learning, tangential). Having clearer understanding of the target audience could generate more motivating and engaging materials for learners.

This article examines the production of educational animations, a tool for business model proposal, and presents examples of the use of the model as a form of assessment that may evidence the actions that have been and could be taken, if the model is used at the conception phase of a given animation. The examples show some uses of the canvas.

\section{Animation Educational and Participative Design}

The first step to develop the canvas was modules of definition and specification. This goal required a literature review.

There are different settings for the animation definition. Lowe and Schnotz [15] define it as pictorial representation that varies over time, a form of representation and information transmission. Thomaz and Johnston [30] emphasize the animation as a media to motivate and transmit emotions. Since the study was focused on educational animation, it is expected that both visions appear balanced in design process.

This process is often guided through steps, and the entertainment industry established some animation design models [3, 11, 12, 20, 27, 29, 30, 32]. Basically, the models present four phases: conception, pre-production, production and postproduction.

The conceptual phase reaches the end with the Animatic production. The Animatic is a preview of the animation, a kind of animated storyboard with times, sounds and movements planned [11]. The other phases are responsible to complete the production accordingly to the animatic.

The presented models are appropriate to develop animations focused in entertainment but they do not address educational issues, even in the conceptual phase. In addition, the lack of a process to develop educational animations usually transfers the animation concept phase to designers or to the teachers. The conception is based on designers/teachers experience and feelings, it depends of each particular designer or designer team allocated to develop the animation, thus the conception phase does not consider or consider partially the real needs of the stakeholders and the project objectives.

As already mentioned before, it is considered in this paper as stakeholders of educational animations: content creators (educators in general), designers (animation conception and production), the teachers' users (indirect users) and apprentices (direct users). To serve them, the adoption of design practices that enable collaboration and effective participation of stakeholders in the process of generating these animations is 
needed. This article refers to the processes of user-centered design, and more specifically the participatory design. There are several definitions for participatory design, to Muller, and Haslwanter Daytorn [24] this term arising from studies of HCI can be defined as "is that the ultimate users of the software make effective contributions that reflect their own perspectives and needs, somewhere in the design and development lifecycle of the software".

However, this research adopts what Baranaukas, Martins and Valente [5] call codesign, a form of design that has bases in participatory design, but it gathers people who do not share the same work context (teachers, students and developers), and who will benefit from the product's results, view that has been an emphasis on human mediation for making animation. Co-design is understood "as the action to work together with people through various artifacts (including pencils and paper prototype systems, narratives, ethnographic research, etc.) to clarify the meanings they construct " this option is necessary if one wants to narrow the gap between the results or the product of the expectations of the people most impacted by the projected solution.

Thinking of these perspectives many tools were surveyed. In HCI there are many tools and techniques for software design. Muller, Haslwanter and Daytorn offer 61 ways to work with participatory design, with the main advantages for its use in projects being the possibility of democratic and social participation of different professionals, efficiency and effectiveness and provided a greater acceptance by users [24].

By presenting these advantages, it was adopted the use of participatory and usercentered design tools as a basis for the design of educational animations.

Of course there are big productions made by film studios that have a comprehensive roadmap and can certainly balance these items. However designers, professionals and teachers who do not hold this training or resources make a large part of the learning materials, mainly for public schools. Therefore, to assist these developers suggested the Business Model Generation. It is a tool for business planning, but it can assist in the development of materials for education.

This Canvas has some features that can help developers and teachers, therefore, treat the course material as a product and direct it to the students is a proposal that meets all the new trends of the interacting education.

\section{Business Model Generations}

According to Osterwalder, A. \& Pigneur, Y., the Business Model Generation Canvas is structured to describe, analyze and design business models. The union of business techniques, strategies and concepts, forms this tool.

Figure 2 shows nine categories defined by the model; they address specific issues to plan a business. Modules show the task segmentation and prioritization (inputs and outputs) and that they can be completed collaboratively (with stickers), what differentiates the canvas of a conceptual map $[9,25,26]$. 


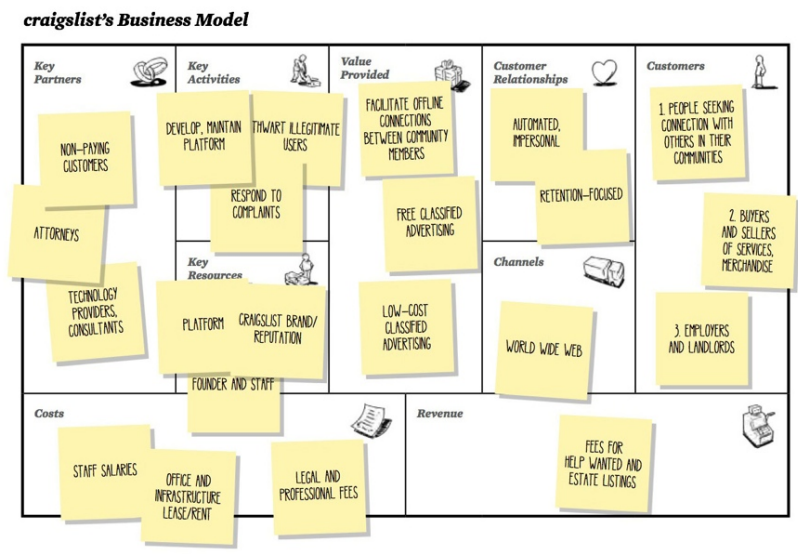

Fig. 1. Business Model Canvas [25]

The business model was adopted because the animation is treated as a product that needs to pass through processes and need to understand and work with different areas of expertise. Such processes depend on settings and complex concepts in education, technology and design, different fields that do not always share their concepts.

Educational animation can be considered products that need to be designed to provide situations and teach, which does not necessarily only depend on technical factors. The playful, motivation and entertainment can assist in this process.

In the book Business Model Generation has numerous motives and uses that canvas has acquired in worldwide. Among the main reasons for its adoption by entrepreneurs the BMG authors mention these: the canvas allows the visualization of links between parts of a process, addresses the problem (the business) holistically, presenting and exhibiting the most varied details; unifies different language experts which helps to clarify the perception of process and product; confronts actions with prospects of success and shows the entire staff implications, actions and prospects of the business.

All these vantages can be used for designing animations: best view, the holistic view, the exposure of details, the unification of process' terms can assist in the production of animation. The use of this tool can professionalize the production of educational animation and consequently improve education itself by offering an alternative to this medium be used efficiently not only just for entertainment, but also for learning.

\section{$4 \quad$ Structuring the Model}

The BMG canvas was the inspiration to define a canvas that helps the development of the conceptual phase of an educational animation. The proposed canvas, as a modular and collaborative tool, can help to solve or minimize this problem. Note that the 
current canvas is restricted to the conceptual phase, a crucial part of the educational animation design.

Figure 2 shows the initial proposal of a canvas-based business model. The model uses four modules and an integration scheme. These modules were designed to meet the 4 stakeholders and list the necessary elements to suit each group and the resources that need to be defined for each animation. The elements of each module were defined based on a bibliographic research and each module treats a specific part of the design process:

1. Content - what teach? - Type, subject, age, pedagogical line $[1,2,7,10,21,23$, 33];

2. Objectives - why teach? - Motivate, illustrate, involve, visualize, thrill $[1,2,7,31$, 33];

3. Resources - how teach? - Physical support, required resources and presentation types $[1,2,3,4,6,7,8,13,14,15,16,17,18,19,21,22,28,31]$;

4. Target-public - for whom? Indirect and direct users [2].

\begin{tabular}{|c|c|c|c|c|}
\hline Content & Objetives & \multicolumn{3}{|l|}{ Resources } \\
\hline What teach? & Why teach? & \multicolumn{3}{|l|}{ How teach? } \\
\hline \multirow{5}{*}{$\begin{array}{l}\text { Type: } \\
\text { Subject: } \\
\text { Associated: } \\
\text { Age: } \\
\text { Pedagogical line: }\end{array}$} & \multirow{5}{*}{$\begin{array}{l}\text { Motivate } \\
\text { Illustrate } \\
\text { Involve } \\
\text { Visualize } \\
\text { Thrill }\end{array}$} & Physical support & Required resources & Presentations types \\
\hline & & \begin{tabular}{|l} 
Suport: \\
Computer \\
Tablet \\
Cinema \\
Mobile
\end{tabular} & \multirow[t]{4}{*}{$\begin{array}{l}\text { Acessibility } \\
\text { Usability } \\
\text { Cognitive factors }\end{array}$} & \multirow[t]{4}{*}{$\begin{array}{l}\text { Visual: } \\
\text { Graphics Language } \\
\text { Sound } \\
\text { Aesthetics } \\
\text { Verbal }\end{array}$} \\
\hline & & $\begin{array}{l}\text { Environment: } \\
\text { Classroom } \\
\text { Laboratory } \\
\text { Home }\end{array}$ & & \\
\hline & & $\begin{array}{l}\text { Technique: } \\
\text { Direct } \\
\text { Pose-to-pose }\end{array}$ & & \\
\hline & & Form: 2D 3D & & \\
\hline \multicolumn{5}{|l|}{ For whom? } \\
\hline \multicolumn{2}{|l|}{ Indirect users } & \multicolumn{3}{|l|}{ Direct users } \\
\hline \multicolumn{2}{|l|}{ Needs of teachers } & \multicolumn{3}{|l|}{ Needs of students } \\
\hline
\end{tabular}

Fig. 2. First Canvas for design of educational animations

However, this initial model does not hierarchizes input or output for the shares and no inserts modules and possible elements that could go into each phase, so he was restructured as shown in figure 3 , where it has an order which lists objectives, content and resources. These modules are based on the key decisions to be made in the conceptual phase.

The modules created are only for illustration and may be added others according to the needs of the project. With this we can generate relationships, justify actions and allow the participation of other experts and other areas that may generate demands for the animation. 


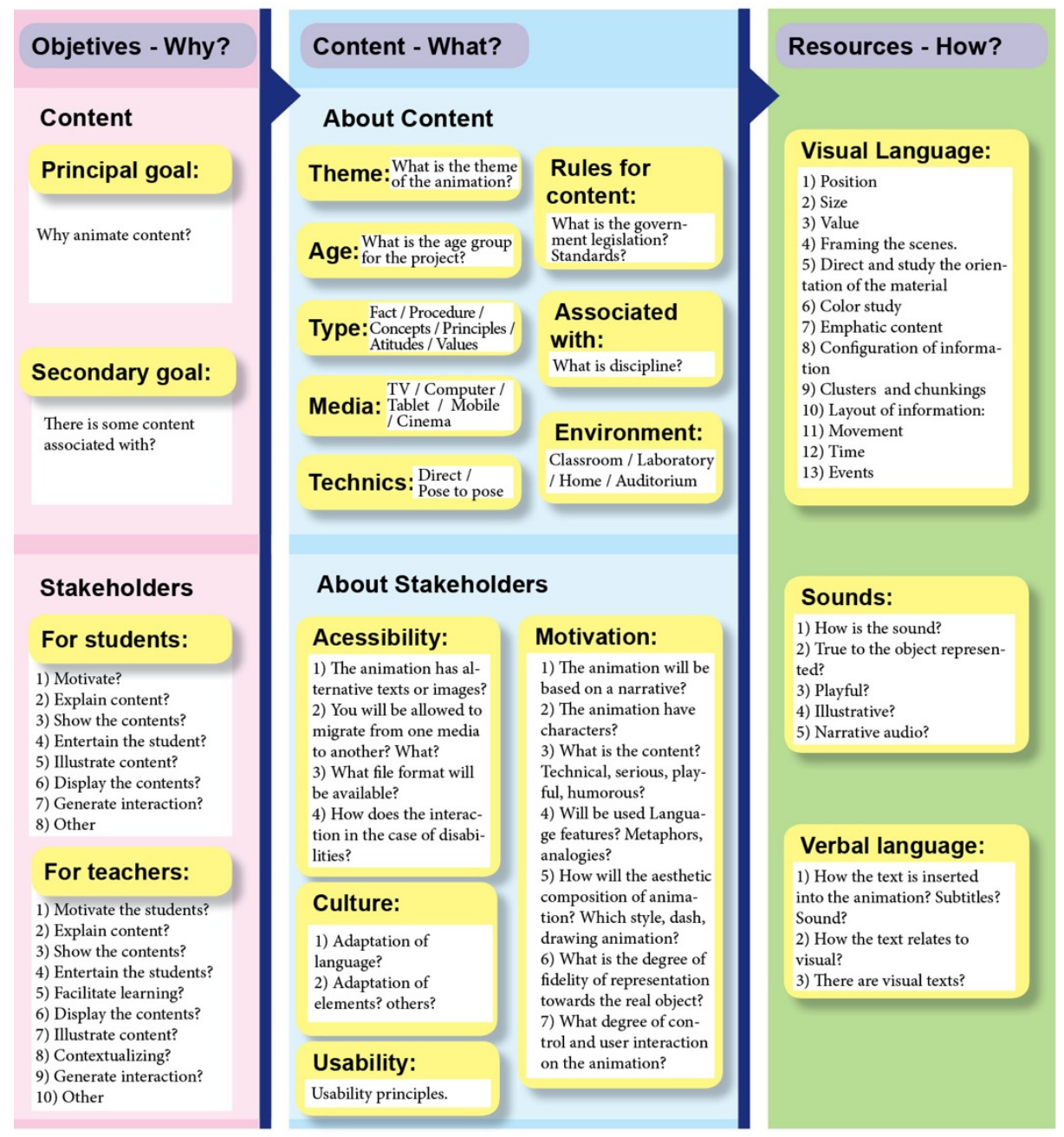

Fig. 3. Ultimate canvas for the Design of educacional animations

How the interests of stakeholders are different, with the generation of this canvas leave clearer decisions and requirements of the project for all involved. These modules are the result of recommendations from the dissertation of Alves [2]. Therefore, for each module have a set of questions that can be answered to establish the requisites (Table 1).

This representation shows a wider view of the animation providing an overview of the project requirements and of the stakeholders (teachers and designers), demonstrating how each action was taken and justifying each step of production.

The modules are interconnected and each choice provides a new perspective for the construction or the possibility of inclusion of other elements. 
Table 1. Questions to fill the canvas

\section{Evaluation of educational animation}

\section{Objectives - Why?}

1) Principal goal: Why animate content?

2) Secondary goal: There is some content associated with?

\begin{tabular}{l|l}
\hline Functions - Stakeholders \\
\hline For students: & For teachers: \\
\hline Motivate? / Explain content? / Show the & Motivate the students? / Explain content? / Show the contents? \\
contents? / Entertain the student? / Illu- & / Entertain the students? / Facilitate learning? / Display the \\
strate content? / Display the contents? / & contents? / Illustrate content? / Contextualizing? / Generate \\
Generate interaction? / Other & interaction? / Other \\
\hline
\end{tabular}

\begin{tabular}{|c|c|}
\hline \multicolumn{2}{|l|}{ Content - What? } \\
\hline Theme: & What is the theme of the animation? \\
\hline Age: & What is the age group for the Project? \\
\hline Type: & Fact / Procedure / Concepts / Principles / Attitudes / Values \\
\hline Media: & TV / Computer / Tablet / Mobile / Cinema \\
\hline Technics: & Direct / Pose to pose \\
\hline Rules for content: & What is the government legislation? Standards? \\
\hline Associated with: & What is discipline? \\
\hline Environment: & Classroom / Laboratory / Home / Auditorium \\
\hline Accessibility: & $\begin{array}{l}\text { 1) What is the target? } \\
\text { 2) The animation has alternative texts or images? } \\
\text { 3) You will be allowed to migrate from one media to another? What? } \\
\text { 4) What file format will be available? } \\
\text { 5) How does the interaction in the case of disabilities? }\end{array}$ \\
\hline Usability & Usability principles. \\
\hline Culture: & 1) Adaptation of language, elements? / Others \\
\hline Motivation: & $\begin{array}{l}\text { 1) The animation will be based on a narrative? } \\
\text { 2) The animation has characters? } \\
\text { 3) What is the content? Technical, serious, playful, humorous? } \\
\text { 4) Will be used Language features? Metaphors, analogies? } \\
\text { 5) How wills the aesthetic of animation? Which style, dash, drawing animation? } \\
\text { 6) What is the degree of fidelity of representation towards the real object? } \\
\text { 7) What degree of control and user interaction on the animation? }\end{array}$ \\
\hline
\end{tabular}

\section{Resources - How?}

Visual lan- Syntactic composition:

guage: $\quad$ 1) Analyzes the Position: position of the frames (physical position or sequence of animation that can be analyzed through the structuring of keyframes).

2) Analyzes the size: the size and scale of the elements within the frame of the animation. In the case of events the issue of macro and micro situations that make up the information.

3) Analyzes the value: texture, volume and colors; use of dimensions (2D, 3D).

4) Analyzes the framing shots.

5) Drive a study of the orientation of the material: the gaze direction by direction indicators (arrows, textual, narration or sound) or motion.

6) Conducts studies of color: hue and saturation, textures, real and artificial, static color patterns and color patterns of events and dramatic situations. 
Table 1. (continued)

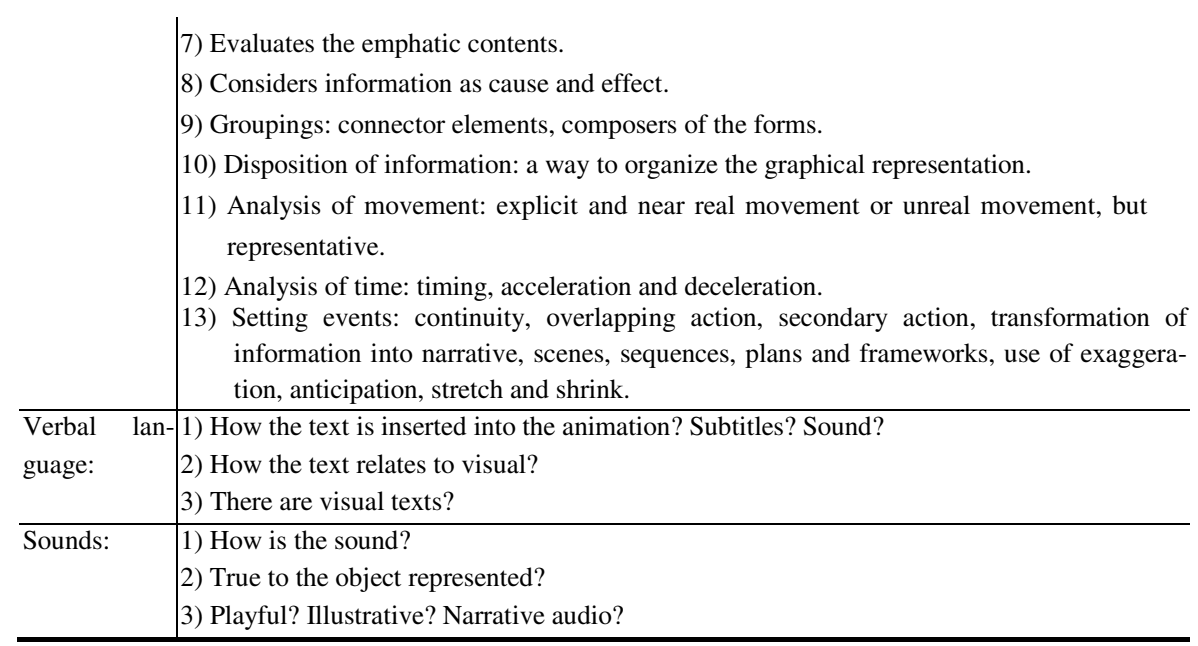

This model is still being tested but, to justify the choice of the Business Model Generation, an initial test with existing animations has been made. This strategy was adopted to justify the use of BMG and show the effects could provide a canvas in the design of educational animations process.

For this, 2 animations were selected in an intentional non-probabilistic sample to demonstrate how the canvas would work before applying it in a real design process. The selected animations are freely available on Youtube ${ }^{\circledR}$. The two animations were selected because they have similar contents but different goals. The first is a playful and informative while, the other presents technical and informative content. The authors performed the assessment presented; therefore, the participation of experts and training of the variables that could be done by more people (which will be done in the future) would be necessary. The next section shows the results of these analyses.

The animations were chosen due to submit the same theme (greenhouse) but with different structures and different ways of presenting information. To demonstrate these differences form the canvas following built based on the proposed model.

The first animation (Figure 4) analyzed belongs to a series of Brazil animations called Collective conscious, created for Canal Futura ${ }^{\circledR}$, a TV channel linked to education. The animation was created by $A k a t u 囚$, which values the conscious consumption, HP and Canal Futura® company.

The analysis revealed some characteristics displayed by animation that may have been thought of in his briefing. The fun aspect, intended to teach values and concepts and generate reflection, it is reflected in the attitudes of the characters and the metaphors used. The use of colors, emotional, and moral appeals give an aspect of humor and attract learners' attention. The canvas can explicit the elements that have been used in the presentation, which provides the possibility of generating an assessment document that can be used as requirements document for the creation. 
The second animation evaluated (Figure 5) also addresses the greenhouse and it was designed by Mamute Midia ${ }^{\circledR}$ for the INPE (Portuguese for Brazilian National Space Research Institute). Its analysis shows similar information when compared to the first animation, but with a different design. The animation turned into an animated infographic in 3D, with visual text (written) and spoken data. This animation uses analogies and even accessibility options (texts spoken and written). It aims to transmit technical information and to offer points of interaction with the content for the students.

The two canvas built showed different actions taken for each animation to try to achieve the needs of each one.

The canvas can also show that each requirement can require some different elements. For example, the first issue presented need the motivational factors that allowed the adoption of animated characters that was not used in the second animation that valued the real information and the teaching content.

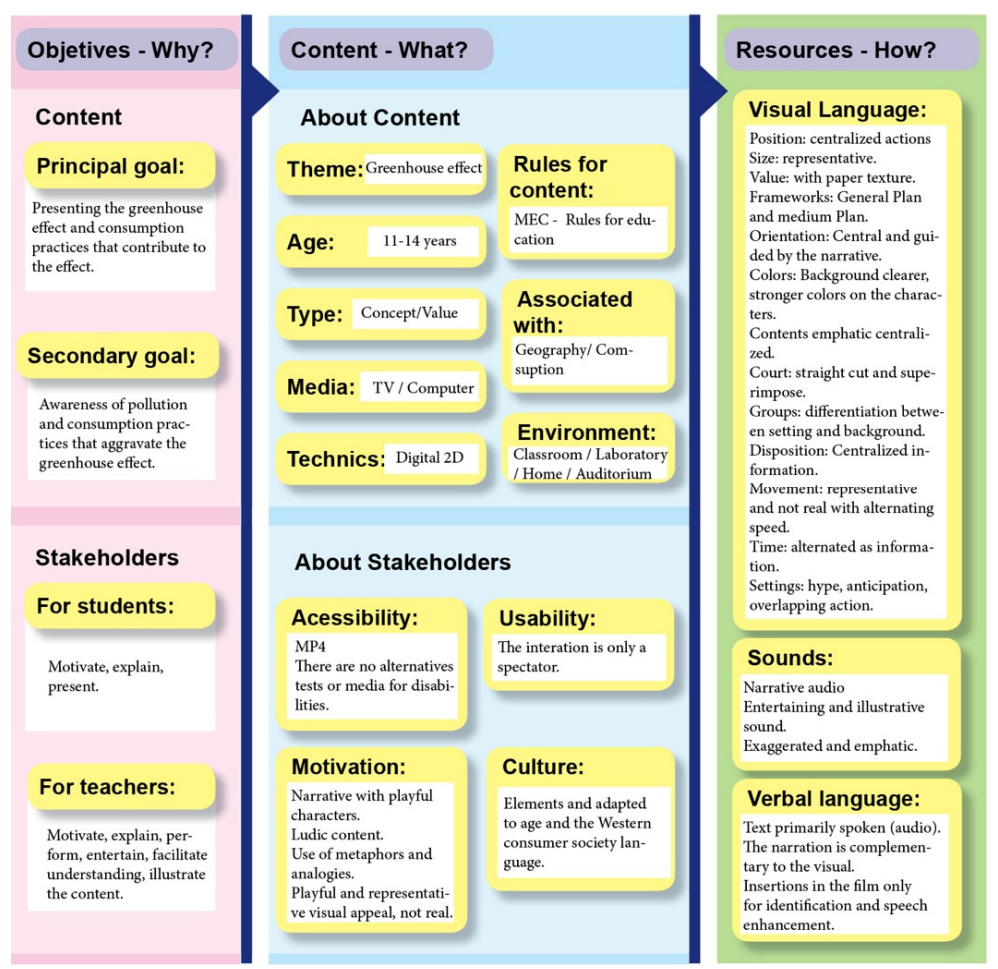

Fig. 4. Canvas of evaluation: Animation "Consciente Coletivo" episode 2. <http://www. youtube.com/watch?v=EEWturRPRuI\&feature=c4-overview-vl\&list=PL0799B2AEDB98CC4D> Access in Feb 01. 2014. 


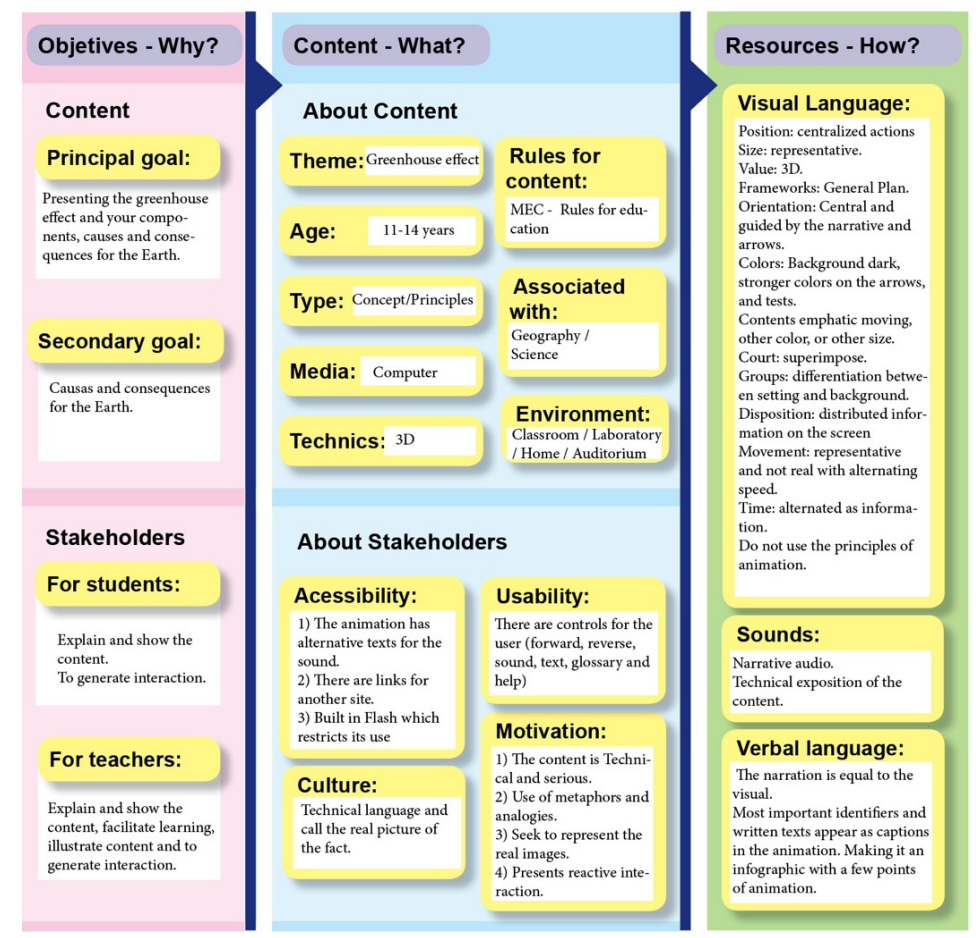

Fig. 5. Canvas of evaluation: Animation "Efeito Estufa" episode 2. $<\mathrm{http} / / /$ videoseducacionais. cptec.inpe.br/swf/mud_clima/02_o_efeito_estufa/02_o_efeito_estufa.shtml> Access in Feb 01. 2014.

This test is insufficient to support the use of the canvas, but they have showed that their use may become clearer reports and briefings and visibly to justify the choices of developers.

\section{Conclusion}

The authors consider that this model:

a) will allow an holistic, modular and flexible view of the design process,

b) will increase the amount and the quality of the participatory decisions and

c) will help to improve the quality of the educational animations produced.

The idea of Business Canvas can help the designers to work in an interdisciplinary and collaborative perspective, can reduce design errors and approximate the perspective of materials for teachers and students by providing best learning experience.

As future work, more tests on actual production situations animations are needed to evaluate the use of canvas as a form of animation design. The next step will consist of a consultation with experts and a case study on the use of the tool in a given period of time in a company's actual educational animation. 
Acknowledgments. The financing of CAPES.

\section{References}

1. Ainsworth, S.: How do animations influence learning? School of Psychology and Learning Sciences Research Institute. University of Nottingham, Nottingham (2008)

2. Alves, M.M.: Design of educational animation: recommendations of content, graphical presentation and motivation for learning. Master's Thesis. PPGDesign. UFPR, Curitiba (2012)

3. Barbosa Jr., A.L.: Art of Animation, 2nd edn. Senac, São Paulo (2005)

4. Baer, K.: Information design workbook. Rock Port Publishers, Inc., USA (2008)

5. Baranauskas, M.C.C., Martins, M.C., Valente, J.A.: Codesign de redes digitais: tecnologias e educação a service da inclusão social. Penso, Porto Alegre (2013)

6. Bertin, J.: The Neográfica and information processing. Editora da UFPR, Curitiba (1986)

7. Clark, R.C., Lyons, C.: Graphics for learning: proven guidelines for planning, designing and evaluating visuals in training materials. John Wiley \& Sons, New Jersey (2010)

8. Csikszentmihalyi, M.: Flow: the psychology of optimal experience. Harper Perennial Modern Classics Edition, USA (1990)

9. Elbers, B.F.: Designing innovative business models: A methodology for structured business model innovation (Master's thesis) (2010), Retrieved from

http: //alexandria.tue.nl/extra2/afstversl/

tm/Elbers\%20F.A. $\% 202010$.pdf (accessed October 2013)

10. Filatro, A.: Instructional Design in practice. Pearson Education do Brasil, São Paulo (2008)

11. Furniss, M.: The Animation Bible: a guide to everything - from flipbooks to flash. Laurence King Publishing, London (2008)

12. Laybourne, K.: The Animation Book: A Complete Guide to Animated Filmmaking-From Flip-Books to Sound Cartoons to 3- D Animation. Three Rivers Press, New York (1998)

13. Löbach, B.: Bases for configuration of industrial products. Blucher, São Paulo (2001)

14. Lowe, R.: Beyond "eye-candy": improving learning with animation. Curtin University of Technology, USA (2001)

15. Lowe, R., Schnotz, W.: Learning with animation: research implications for design. Cambridge University Press, New York (2008)

16. Mackinlay, J.D.: Automating the design of graphical presentation of relational information (1986), http: / / www.google.com.br/

\#hl=pt-BR\&Source=hp\&q=\%22Automating+the+design+of+graphical+

presentations+of+relational+information $22 \& a q=$

$\mathrm{f} \& \mathrm{aq} i=\& \mathrm{aq} \mathrm{l}=\& \mathrm{Oq}=\& \mathrm{gs} \_r \mathrm{fai}=\& \mathrm{fp}=90 \mathrm{~b} 51830697 \mathrm{~d} 5712$

(accessed in May 10, 2010)

17. Malone, T.W.: What makes computer games fun? In: ACM, pp. 162-169 (1980)

18. Malone, T., Lepper, M.: Making learning fun: A taxonomy of intrinsic motivations for learning. In: Snow, R., Farr, M. (eds.) Aptitude, Learning, and Instruction: III. Conative and Affective Process Analyses, pp. 223-253. Erlbaum, Hillsdale (1987)

19. Malone, T.: Heuristics for designing enjoyable user interfaces: lessons from computer games. Xerox Palo Alto Research Center (1981)

20. Marx, C.: Writing for animation, comics and games. Focal Press, UK (2007)

21. Mayer, R.E.: Multimedia learning, 2nd edn. Cambridge University Press: Library of Congress (2007) 
22. Mijksenaar, P.: Visual function: an introduction to information design. Princenton Architectural Press, New York (1997)

23. Ministry of Education. Notice of public call 2 of 26 February 2010. Diário oficial da União, seção 3, no 39 (2010)

24. Muller, M.J., Haslwanter, J.H., Dayton, T.: Participatory Practices in the software lifecycle. In: Handbook of Human-Computer Interaction, Elsevier Science B. V. (1997)

25. Osterwalder, A., Pigneur, Y.: Business model generation: A handbook for visionaries, game changers, and challengers. Wiley, Hoboken (2010)

26. Osterwalder, A., Pigneur, Y., Tucci, C.L.: Clarifying business models: Origins, present and future of the concept. Commnications of the Association for Information Systems (2005)

27. Pixar studio. Production process, http://www.pixar.com/behind_the_scenes (acesso em September 19, 2010)

28. Preece, et al.: Interation design: beyond human-computer interaction. Bookman, Porto Alegre (2005)

29. Taylor, R.: Enciclopedia de técnicas de animación, 2nd edn. Acanto, Barcelona (2004)

30. Thomas, F., Johnston, O.: The illusion of life: Disney animation (1995)

31. Weiss, R.E., Knowlton, D.S., Morrison, G.R.: Principles for using animation in computerbased instruction: theoretical heuristics for effective design. Computer in Human Behavior (2002)

32. Willians, R.: The animators survival kit. A manual of methods. Faber and Faber Limited, London (2009)

33. Zabala, A.: The educational practice: how to teach. Artmed, Porto Alegre (1998) 